\title{
Transverse Expansion and Stability after Segmental Le Fort I Osteotomy versus Surgically Assisted Rapid Maxillary Expansion: a Systematic Review
}

\author{
Thomas Starch-Jensen ${ }^{1}$, Tue Lindberg Blæhr ${ }^{1}$ \\ ${ }^{1}$ Department of Oral and Maxillofacial Surgery, Aalborg University Hospital, Aalborg, Denmark.
}

\author{
Corresponding Author: \\ Thomas Starch-Jensen \\ Department of Oral and Maxillofacial Surgery \\ Aalborg University Hospital \\ 18-22 Hobrovej, DK-9000 Aalborg \\ Denmark \\ Phone: +4597662798 \\ Fax: +4597662825 \\ E-mail: thomas.jensen@rn.dk
}

\begin{abstract}
Objectives: The objective of the present systematic review was to test the hypothesis of no difference in transverse skeletal and dental arch expansion and relapse after segmental Le Fort I osteotomy versus surgically assisted rapid maxillary expansion. Material and Methods: A MEDLINE (PubMed), Embase and Cochrane library search in combination with a hand-search of relevant journals was conducted by including human studies published in English from January 1, 2000 to June 1, 2016.

Results: The search provided 130 titles and four studies fulfilled the inclusion criteria. All the included studies were characterized by high risk of bias and meta-analysis was not possible due to considerable variation. Both treatment modalities significantly increase the transverse maxillary skeletal and dental arch width. The transverse dental arch expansion and relapse seems to be substantial higher with tooth-borne surgically assisted rapid maxillary expansion compared to segmental Le Fort I osteotomy. The ratio of dental to skeletal relapse was significantly higher in the posterior maxilla with tooth-borne surgically assisted rapid maxillary expansion. Moreover, a parallel opening without segment tilting was observed after segmental Le Fort I osteotomy.

Conclusions: Maxillary transverse deficiency in adults can be treated successfully with both treatment modalities, although surgically assisted rapid maxillary expansion seems more effective when large transverse maxillary skeletal and dental arch expansion is required. However, considering the methodological limitations of the included studies, long-term randomized studies assessing transverse skeletal and dental expansion and relapse with the two treatment modalities are needed before definite conclusions can be provided.
\end{abstract}

Keywords: orthodontics; orthognathic surgery; palatal expansion technique; review.

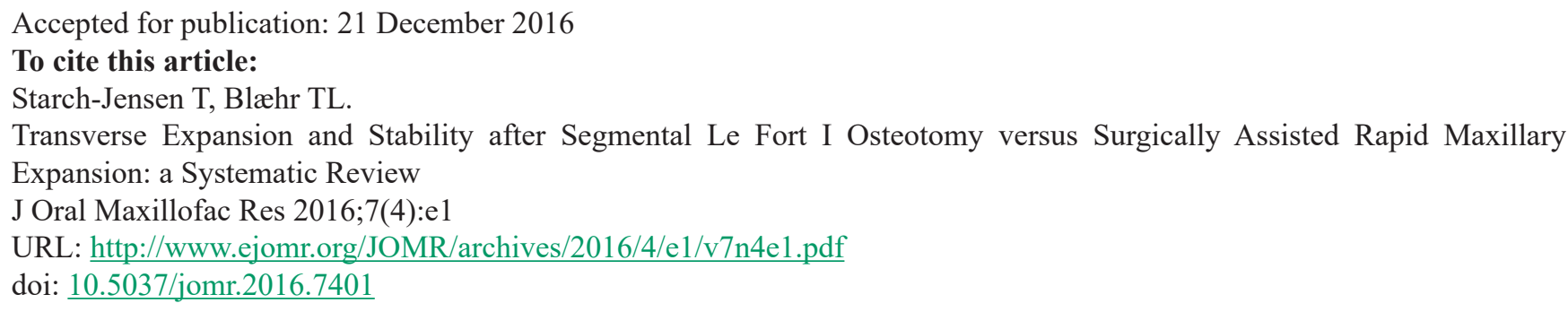




\section{INTRODUCTION}

Transverse maxillary hypoplasia, in adolescents and adults, is characterized by a narrow maxillary apical base, unilateral or bilateral cross-bite, a high narrow palatal vault and crowded misaligned teeth [1]. Minor maxillary width discrepancies in adults can often be corrected solely by orthodontic expansion, while surgical correction is recommended when a considerable transverse expansion of the maxilla is needed [1-3]. Segmental Le Fort I osteotomy is a predictable, well-established surgical technique that is commonly used to correct maxillary transverse discrepancies up to $6-7 \mathrm{~mm}$ in adults [4]. However, transverse expansion of the maxilla with a segmental Le Fort I osteotomy is often associated with postsurgical instability and relapse [5-8]. Few shortterm studies have estimated the transverse stability after segmental Le Fort I osteotomy and dental cast measurements have disclosed a transverse relapse of $30 \%$ at the premolars and $49 \%$ at the second molars 2 years after debanding [5-8]. Different methods have been recommended to reduce the potential for transverse instability involving bone grafts or allografts at the palatal osteotomy site, use of palatal bars and expanders, interocclusal splints, transpalatal bone-anchored devices or fixation of the palatal vault with biodegradable plates $[\underline{5}, \underline{9-12}]$. However, transverse maxillary expansion with a segmental Le Fort I osteotomy is still considered the least stable surgical orthognathic procedure and overexpansion is frequently recommended $[\underline{4}, \underline{6}, \underline{7}, \underline{13}]$.

Surgically assisted rapid maxillary expansion (SARME) is a combination of orthodontics and distraction osteogenesis, which provides dental arch space for alignment of teeth and minimizes transverse maxillary relapse. SARME has become a common surgical method in treating postadolescent patients with dental crowding and severe transverse maxillary hypoplasia with a closed midpalatal suture $[\underline{1}, \underline{2}, 14-18]$. SARME has been anticipated to ensure a better transverse stability compared to a segmental Le Fort osteotomy. On the contrary, it has also been postulated that the transverse stability of SARME is not significantly greater than segmental Le Fort I osteotomy [7]. Several reviews have demonstrated that SARME increases the maxillary width at both

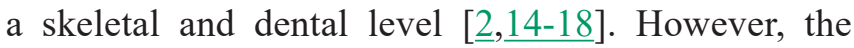
reported postsurgical stability varies considerably and few studies have differentiated between the skeletal and occlusal outcome. Moreover, linear measurements on plaster models of the patient's dentition and twodimensional radiography are predominantly used to assess the efficacy of SARME on the dento-skeletal complex. Traditionally, a tooth-borne palatal expander has been used to expand the maxillary width and arch. However, a tooth-borne distraction device seems to cause alveolar bending and dental tipping. Therefore, SARME with a bone-borne palatal expander has been used more frequently during the last decade to minimize tipping of the dentition and to generate a parallel skeletal expansion of the bony segments. However, a recently published systematic review concluded that there is a need for well-designed clinical trials evaluating the effects of tooth-borne and bone-borne SARME, due to weak evidence for less dental tipping with a bone-borne device compared to a tooth-borne expander [15].

Transverse maxillary deficiencies usually compromise both the anterior and posterior part of the maxilla, but a narrow maxillary apical base without posterior cross-bite and anterior crowding are often seen. Segmental Le Fort I osteotomy yields a dissimilar skeletal and dental expansion pattern compared to SARME and the two treatment modalities should therefore be used for different clinical cases. Segmental Le Fort I osteotomy involves the "down-fracture" technique and direct three-dimensional repositioning of the maxilla, whereas SARME indirectly expands the maxilla by means of distraction osteogenesis. The type and placement of a bone-borne distraction device in the palate, the rate of distraction and different maxillary osteotomies may influence the magnitude of transverse expansion by SARME. Preoperative quantification of the required transverse expansion in each region of the maxilla is therefore necessary to minimize skeletal and dental relapse. Moreover, an individual, patient specific decision if tooth-borne or bone-borne devices are preferred for SARME with respect to device specific advantages has been recommended [19]. However, individualization of the surgical technique according to the region affected by the transverse deficiency is rarely described in the literature $[\underline{20}, \underline{21}]$, and the transverse maxillary skeletal and dental arch expansion and relapse after segmental Le Fort I osteotomy compared to SARME has never been assessed specifically in a systematic review. Consequently, segmental Le Fort I osteotomy and SARME with tooth-borne and bone-borne appliances are two dissimilar treatment modalities used for surgical correction of transverse maxillary discrepancies. However, the transverse maxillary expansion pattern and the skeletal and dental stability with the two treatment modalities are not well-elucidated in the literature. 
The objective of the present systematic review was to test the hypothesis of no difference in transverse maxillary skeletal and dental arch expansion and relapse with segmental Le Fort I osteotomy compared to surgically assisted rapid maxillary expansion.

\section{MATERIAL AND METHODS Protocol and registration}

The methods of the analysis and inclusion criteria were specified in advance and documented in a protocol. The review was registered in PROSPERO, an international prospective register of systematic reviews. The protocol can be accessed at:

http://www.crd.york.ac.uk/PROSPERO/display record.asp?ID=CRD42016053612.

Registration number: CRD42016053612.

The present systematic review was conducted in accordance with the Preferred Reporting Items for Systematic reviews and Meta-Analyses (PRISMA) statement for reporting systematic reviews [22].

\section{Types of publications}

The review included studies on humans published in the English language. Letters, editorials, $\mathrm{PhD}$ theses, letters to the editor, case reports, abstracts, technical reports, conference proceedings, animal or in vitro studies and literature review papers were excluded.

\section{Types of studies}

The review included all human randomized clinical trials, prospective cohort studies, case-control studies, case series or retrospective studies comparing transverse skeletal and dental arch expansion and relapse after segmental Le Fort I osteotomy compared to SARME.

\section{Types of outcome measures}

- Transverse skeletal expansion and relapse of the maxilla.

- Transverse dental arch expansion and relapse of the maxilla.

- Definitive transverse dental arch expansion of the maxilla. Defined as the final reported measurement of the maxillary dental arch width.

- Frequency of complications.

- Patient-reported outcome measures.

\section{Information sources}

The search strategy incorporated examinations of electronic databases, supplemented by a thorough hand-search page by page of relevant journals including "British Journal of Oral and Maxillofacial Surgery", "International Journal of Oral and Maxillofacial Surgery", "Journal of Craniofacial Surgery", "Journal of Cranio-Maxillo-Facial Surgery", "Journal of Oral and Maxillofacial Surgery", "Oral and Maxillofacial Surgery" and "Oral Surgery Oral Medicine Oral Pathology Oral Radiology". The manual search also included the bibliographies of all articles selected for full-text screening as well as previously published reviews relevant for the present systematic review. Two of the reviewers (TJ and TB) performed the search. Any disagreements were resolved by consensus between the two observers.

\section{Search}

A MEDLINE (PubMed), Embase, and Cochrane Library search was conducted by including studies published in English from January 1, 2000 to June 1, 2016. The search strategy utilized a combination of Medical subject heading (MeSH) and free text terms:

1. exp Osteotomy, Le Fort/ (1751);

2. (Le Fort I or Le Fort 1).mp. (1458);

3. or/1-2 (2469);

4. SARME.mp. (86);

5. SARPE.mp. (38);

6. (((osteotomy or surgical*) adj5 (maxillar* or palatal*) $^{*}$ and expansion*).mp. (410);

7. or/4-6 (414);

8. 3 and 7 (130).

\section{Selection of studies}

The PRISMA flow diagram presents an overview of the selection process (Figure 1). The titles of the identified reports were initially screened. The abstract was assessed when the title indicated that the study was relevant. Full-text analysis was obtained for those with apparent relevance or when the abstract was unavailable. The references of the identified papers were cross-checked for unidentified articles. The study selection was performed by two of the reviewers (TJ and TB). Any disagreement was resolved by consensus between the two observers.

\section{Study eligibility}

The inclusion criteria were developed using the PICOS guidelines (Table 1). 


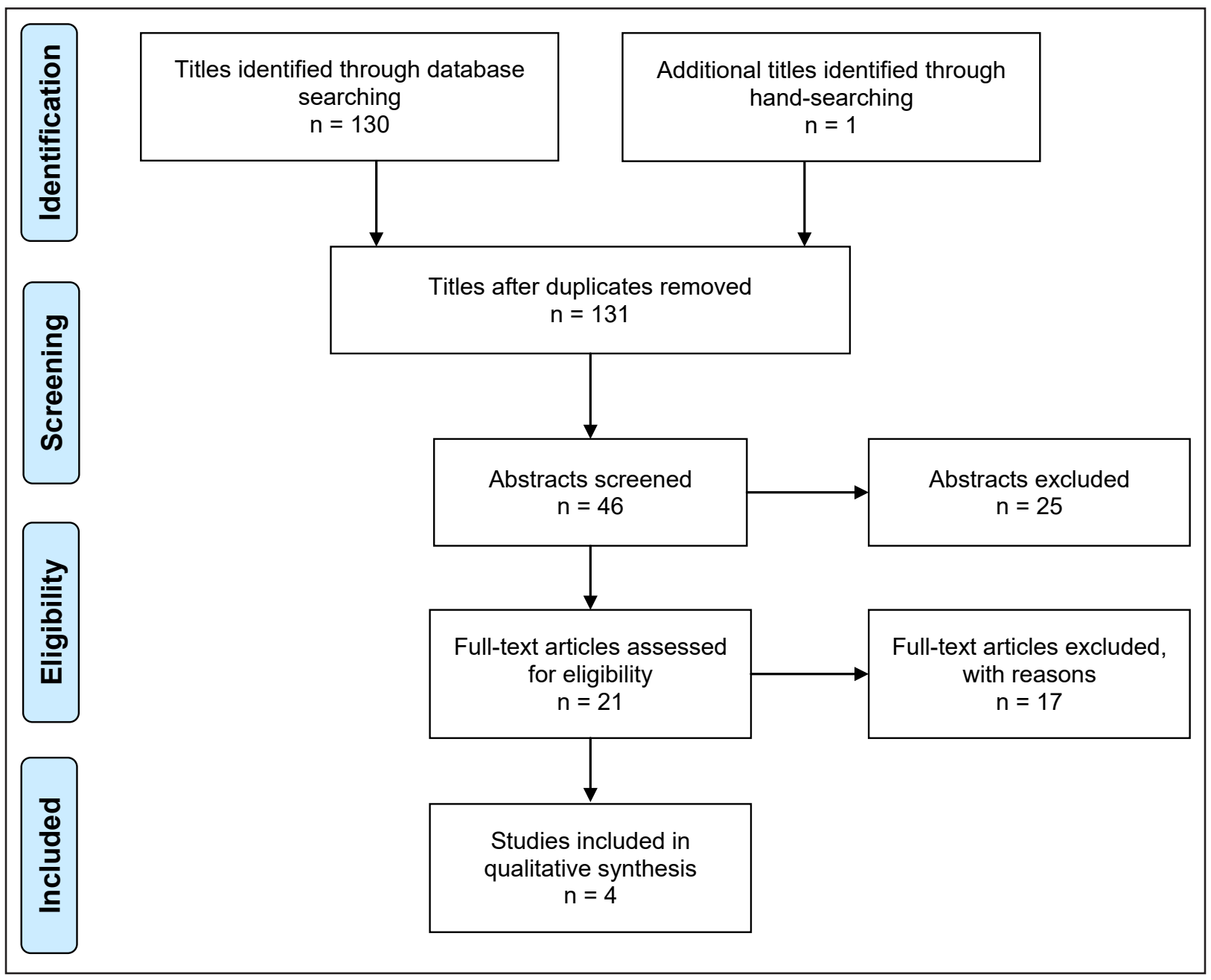

Figure 1. PRISMA flow diagram demonstrating the results of the systematic literature search.

Table 1. PICOS guidelines

\begin{tabular}{l|l}
\hline Patient and population (P) & All adult patients (> 17 years) with a transverse maxillary hypoplasia requiring orthognatic surgery. \\
\hline Intervention (I) & Segmental Le Fort I osteotomy. \\
\hline $\begin{array}{l}\text { Comparator or control } \\
\text { group (C) }\end{array}$ & Surgically assisted rapid maxillary expansion \\
\hline Outcomes (O) & $\begin{array}{l}\text { Transverse dentoalveolar and skeletal expansion and relapse, total dentoalveolar expansion, frequency } \\
\text { of complications and patient-related outcome measure. }\end{array}$ \\
\hline Study design (S) & $\begin{array}{l}\text { Human studies, including randomized controlled trials, controlled clinical trials and retrospective } \\
\text { studies, with the aim of comparing transverse dental and skeletal expansion and relapse after segmental } \\
\text { Le Fort I osteotomy compare to surgically assisted rapid maxillary expansion. }\end{array}$ \\
\hline Focused question & $\begin{array}{l}\text { Are there any differences in the transverse maxillary dentoalveolar and skeletal expansion and relapse } \\
\text { between segmental Le Fort I osteotomy and surgically assisted rapid maxillary expansion? }\end{array}$ \\
\hline
\end{tabular}

\section{Inclusion criteria}

Human studies comparing segmental Le Fort I osteotomy with either tooth-borne or bone-borne SARME were included by addressing the previously described outcome measures. The review exclusively focused on studies applying rigid internal fixation. In addition, at least 5 patients should be included in the study with a minimum of six months follow-up. Studies involving segmental Le Fort I osteotomy with 2-piece or multi-piece interdental osteotomies were included.

\section{Exclusion criteria}

Uncontrolled clinical studies, studies with insufficient description of the performed numbers of surgical procedures, length of follow-up period and studies involving cleft patients or revision were excluded. 


\section{Data extraction}

Data were extracted by one reviewer (TJ) according to a data-collection form ensuring systematic recording of the outcome measures. In addition, relevant characteristics of the study were recorded.

\section{Data items}

The following items were collected from the included articles and arranged in the following fields: patients, surgical technique, transverse deficit, material, follow-up, skeletal expansion, dental expansion, skeletal relapse, dental relapse, total dental expansion, complications and patient-related outcome measures.

\section{Assessment of methodological quality}

The quality assessment of the included studies was undertaken by one review author (TJ) as part of the data extraction process. A methodological quality rating system was used and the classification of the risk of bias potential for each study was based on the following five criteria:

- Random selection in the population (yes/no).

- Definition of inclusion and exclusion criteria (yes/ no).

- Report of losses to follow-up (yes/no).

- Validated measurements (yes/no).

- Statistical analysis (yes/no).

The studies were grouped according to:

- Low risk of bias (plausible bias unlikely to seriously alter the results) if all above-described quality criteria were met.

- Moderate risk of bias (plausible bias that weakens confidence in the results) when one of these criteria were not included.

- High risk of bias (plausible bias that seriously weakens confidence in the results) when two or more criteria were missing.

\section{Statistical analysis}

No meta-analyses could be performed due to the heterogeneity between the studies (different study designs, control groups, and observation periods) [23].

\section{RESULTS \\ Study selection}

Article review and data extraction were performed according to the PRISMA flow diagram. A total of 130 titles were identified and 46 abstracts were reviewed.
Full-text analysis included 21 articles and four studies were finally included in the present systematic review [4, 24-26]. One article was included as the result of hand-searching [24].

\section{Exclusion of studies}

The reasons for excluding studies after full-text assessment were as follows: the study could not be excluded before meticulous reading $(\mathrm{n}=10)$, insufficient description of the number of surgical procedures $(n=3)$, insufficient description of the length of the follow-up period $(n=2)$, case-series with less than 5 patients $(n=2)$.

\section{Study characteristics}

The included studies involved a prospective longitudinal study [25] and three retrospective studies $[4,24,26]$. Transverse skeletal expansion and relapse of the maxilla were reported in two studies [24,25], transverse dental arch expansion and relapse of the maxilla were reported in two studies $[4,25]$, and the definitive dental arch expansion of the maxilla were reported in three studies $[\underline{4}, \underline{24}, 26]$. The frequency of complications were described in two studies $[24,25]$, while patient-reported outcome measures were not reported in any of the included studies.

Cone-beam computed tomography (CBCT) has been used to prospectively estimate the transverse skeletal and dental arch expansion and relapse [25]. Segmental Le Fort I osteotomy was performed in 9 patients with a transverse discrepancy of 3 to $6 \mathrm{~mm}$, whereas SARME with a tooth-borne expander was performed in 4 patients with a transverse discrepancy of more than $6 \mathrm{~mm}$. CBCT was obtained preoperatively, within 1 month postoperatively, and at 6 months postoperatively. Measurements of the skeletal maxillary width change at the greater palatine superior intercanal and the piriform base was used to estimate the skeletal expansion and relapse, while the intermolar and intercanine width distance was used to measure the dental arch expansion and relapse. Dental cast models have been used retrospectively to estimate the transverse dental arch expansion and relapse of the maxilla as well as the definitive dental arch expansion [ㄴ, 26] $]$. The distances between the crowns of the canines and the first molars were measured before surgery, after surgery or distraction, and finally two years after the end of expansion [4]. The study included 10 patients with an intermolar deficit of less than $6 \mathrm{~mm}$, who had undergone segmental Le Fort I and 10 patients with intermolar deficit of more than $6 \mathrm{~mm}$, 
who had undergone tooth-borne SARME [4]. Linear plaster models measurements of the dental arch width between the first premolars and first molars were obtained preoperatively and postoperatively in 18 patients who had undergone segmental Le Fort I osteotomy and 14 patients who had undergone toothborne SARME to estimate the definitive dental arch expansion [26].

CBCT has retrospectively been analysed to estimate the nasal airway distance and the definitive dental arch expansion of the maxilla by measuring the change from the innermost point of the bony floor of the nose to the upper first molar and the distance between the crown of the maxillary canines and the upper first molars [24]. The study included 12 patients, who had undergone two-piece segmental Le Fort I osteotomy with stabilization of the transverse expansion at the nasal floor with a biodegradable plate and 20 patients, who had undergone bone-borne SARME. CBCT was obtained before surgery and 9 months after surgery. The main results are described below and summarized in Table 2.

\section{Synthesis of results}

The studies included revealed considerable variations in design, i.e. amount of transverse expansion, use of tooth-borne or bone-borne distraction appliances, fixation of the palatal expansion with biodegradable plates, length of observation period, and type of outcome measures. Therefore, meta-analyses were not applicable.

\section{Outcome measures}

The result of each outcome measures are presented first and then a short summary is finally provided.

\section{Transverse skeletal expansion and relapse of the maxilla}

Assessment of the transverse skeletal expansion and relapse of the maxilla with the two treatment modalities has been done in two short-term studies $[\underline{24}, \underline{25}]$. In a prospective study using CBCT, the anterior and posterior skeletal expansion was 1.94 (SD 0.93 ) $\mathrm{mm}$ and 3.43 (SD 1.24) $\mathrm{mm}$ with a segmental Le Fort I osteotomy, and 2.25 (SD 1.79) $\mathrm{mm}$ and 0.5 (SD 0.24) $\mathrm{mm}$ with tooth-borne SARME, respectively [25]. The transverse skeletal relapse as evaluated by measurements obtained from 1 month postoperatively to 6 months postoperatively demonstrated that the anterior and posterior skeletal relapse was 0.55 (SD $0.55) \mathrm{mm}$ and $0.86(\mathrm{SD} 0.42) \mathrm{mm}$ with a segmental
Le Fort I osteotomy. The anterior skeletal relapse was 0.74 (SD 0.63) $\mathrm{mm}$ after SARME, while the posterior skeletal width increased by 0.8 (SD 0.54 ) $\mathrm{mm}$. The skeletal width expansion and relapse was significantly changed with a segmental Le Fort I osteotomy, whereas no statistically significant skeletal width changes were observed with SARME, besides the posterior skeletal expansion.

A retrospective analysis of CBCT scans demonstrated a statistically significantly skeletal increase of 2.94 (SD 3.19) $\mathrm{mm}$ with a bone-borne SARME compared to 3.92 (SD 2.74) $\mathrm{mm}$ with a segmental Le Fort I osteotomy involving stabilization of the transverse expansion with a biodegradable plate after 9 months [24]. A more parallel opening without segment tilting was described with a segmental Le Fort I osteotomy.

\section{Summary}

The transverse skeletal maxillary expansion and relapse with the two treatment modalities have been compared in short-term studies using standardized skeletal landmarks on CBCT. Segmental Le Fort I osteotomy seems to create more skeletal expansion in the posterior part of the maxilla compared to toothborne SARME after 1 month, whereas approximately equal anterior and posterior skeletal expansion of the maxilla with the two treatment modalities was observed after 6 month. Segmental Le Fort I osteotomy with fixation of the transverse expansion on the floor of the nose with a biodegradable plate seems to facilitate a more parallel segment shift without tilting of the segments.

\section{Transverse dental arch expansion and relapse of the maxilla}

Transverse dental arch expansion and relapse of the maxilla have been assessed in two studies $[\underline{4}, 25]$. A retrospective analysis of dental cast models obtained preoperatively and post-expansion demonstrated an anterior and posterior dental arch expansion of 2.75 $\mathrm{mm}$ (range 0 to $4.5 \mathrm{~mm}$ ) and $3.75 \mathrm{~mm}$ (range 2.5 to $7.5 \mathrm{~mm}$ ) with segmental Le Fort I osteotomy, and $8.5 \mathrm{~mm}$ (range 4.5 to $10.5 \mathrm{~mm}$ ) and $7 \mathrm{~mm}$ (range 5 to $9.5 \mathrm{~mm}$ ) with tooth-borne SARME, respectively [4]. The transverse dental relapse as evaluated by measurements obtained from post-expansion to 24 months after post-expansion showed that the anterior and posterior dentoalveolar relapse was $0.25 \mathrm{~mm}$ (range -2.5 to $3.5 \mathrm{~mm})(25 \%)$ and $0.75 \mathrm{~mm}$ (range -5 to 0 $\mathrm{mm})(20 \%)$ with a segmental Le Fort I osteotomy, and $2.5 \mathrm{~mm}$ (range -6 to $1 \mathrm{~mm}$ ) $(28 \%)$ and $3 \mathrm{~mm}$ (range -3.5 to $3 \mathrm{~mm})(36 \%)$ with SARME, respectively. 
Table 2. Characteristics of the included studies

\begin{tabular}{|c|c|c|c|c|c|c|c|c|c|c|c|c|c|}
\hline \multirow[b]{2}{*}{ Study } & \multirow[b]{2}{*}{$\begin{array}{c}\text { Year of } \\
\text { publication }\end{array}$} & \multirow[b]{2}{*}{$\begin{array}{c}\text { Patients } \\
\text { (n) }\end{array}$} & \multicolumn{4}{|c|}{ Material and methods } & \multicolumn{7}{|c|}{ Outcome measures } \\
\hline & & & $\begin{array}{c}\text { Surgical } \\
\text { technique }\end{array}$ & $\begin{array}{c}\text { Transverse } \\
\text { deficit } \\
(\mathbf{m m})\end{array}$ & Material & $\begin{array}{c}\text { Follow- } \\
\text { up } \\
\text { (months) }\end{array}$ & $\begin{array}{c}\text { Skeletal expansion } \\
(\mathrm{mm})\end{array}$ & $\begin{array}{c}\text { Dental expansion } \\
(\mathrm{mm})\end{array}$ & $\begin{array}{l}\text { Skeletal relapse } \\
(\mathrm{mm})\end{array}$ & $\begin{array}{l}\text { Dental relapse } \\
\quad(\mathrm{mm})\end{array}$ & $\begin{array}{c}\text { Total dental } \\
\text { expansion } \\
(\mathrm{mm})\end{array}$ & Complications & \begin{tabular}{|c|} 
Patient- \\
related \\
outcome \\
measures \\
\end{tabular} \\
\hline \multirow{2}{*}{$\begin{array}{l}\text { Marchetti } \\
\text { et al. [4] }\end{array}$} & \multirow{2}{*}{2009} & \multirow{2}{*}{20} & $\begin{array}{l}\text { Segmental } \\
\text { LFI: } 10\end{array}$ & $<6$ & \multirow{2}{*}{$\begin{array}{l}\text { Dental } \\
\text { cast }\end{array}$} & \multirow{2}{*}{24} & \multirow{2}{*}{ NR } & \multirow{2}{*}{\begin{tabular}{|c|} 
After expansion: \\
Canine: 2.75 \\
(range 0 to 4.5 ); \\
Molar: 3.75 \\
(range 2.5 to 7.5 ) \\
After expansion: \\
Canine: 8.5 \\
(range 4.5 to 10.5 ); \\
Molar: 7 \\
(range 5 to 9.5 ) \\
\end{tabular}} & \multirow{2}{*}{ NR } & \begin{tabular}{|}
24 months: \\
Canine: -0.25 \\
(range -2.5 to 3.5 ); \\
Molar: -0.75 \\
(range -5 to 0 )
\end{tabular} & \begin{tabular}{|c|}
24 months: \\
Canine: 1.75 \\
(range 0 to 5); \\
Molar: 3.25 \\
(range -1 to 5) \\
\end{tabular} & \multirow{2}{*}{ NR } & \multirow{2}{*}{ NR } \\
\hline & & & $\begin{array}{c}\text { SARME: } \\
10\end{array}$ & $>6$ & & & & & & $\begin{array}{l}24 \text { months: } \\
\text { C: }-2.5 \text {; } \\
\text { M: }-3\end{array}$ & \begin{tabular}{|c|}
24 months: \\
Canine: 5.25 \\
(range 2.5 to 9 ); \\
Molar: 5.25 \\
(range 2.5 to 9.5 ) \\
\end{tabular} & & \\
\hline \multirow{2}{*}{$\begin{array}{l}\text { Seeberger } \\
\text { et al. [24] }\end{array}$} & \multirow{2}{*}{2015} & \multirow{2}{*}{32} & $\begin{array}{l}\text { Segmental } \\
\text { LFI with } \\
\text { BDP: } 12\end{array}$ & \multirow{2}{*}{ NR } & \multirow{2}{*}{$\mathrm{CBCT}$} & \multirow{2}{*}{9} & $\begin{array}{l}9 \text { months: } \\
3.92\end{array}$ & \multirow{2}{*}{ NR } & \multirow{2}{*}{ NR } & \multirow{2}{*}{ NR } & \begin{tabular}{|c|}
9 months: \\
Canine: \\
2.13 (SD 2.4); \\
Molar: \\
4 (SD 3.7) \\
\end{tabular} & \multirow{2}{*}{ None } & \multirow{2}{*}{ NR } \\
\hline & & & $\begin{array}{l}\text { SARME: } \\
20\end{array}$ & & & & $\begin{array}{l}9 \text { months: } \\
2.94\end{array}$ & & & & \begin{tabular}{|c|}
9 months: \\
Canine: \\
6.37 (SD 3.92); \\
Molar: \\
5.09 (SD 5.38) \\
\end{tabular} & & \\
\hline \multirow{2}{*}{$\begin{array}{l}\text { Yao et al. } \\
{[25]}\end{array}$} & \multirow{2}{*}{2015} & \multirow{2}{*}{13} & $\begin{array}{l}\text { Segmental } \\
\text { LFI: } 9\end{array}$ & $<3-6<$ & $\mathrm{CBCT}$ & & $\begin{array}{c}1 \text { months: } \\
\text { AE: } 1.94 \text { (SD 0.93); } \\
\text { PE: } 3.43 \text { (SD 1.24) }\end{array}$ & $\begin{array}{c}1 \text { months: } \\
\text { Canine: } \\
\text { 1.01 (SD 0.68); } \\
\text { Molar: } \\
2.17 \text { (SD 0.9) }\end{array}$ & $\begin{array}{c}6 \text { months: } \\
\text { AE: }-0.55 \text { (SD 0.55); } \\
\text { PE: }-0.86 \text { (SD 0.42) }\end{array}$ & \begin{tabular}{|c|}
6 months: \\
Canine: \\
-0.39 (SD 0.24); \\
Molar: \\
-0.77 (SD 0.38) \\
\end{tabular} & \multirow{2}{*}{ NR } & \multirow{2}{*}{$\begin{array}{c}\text { No surgical } \\
\text { or orthodontic } \\
\text { complications }\end{array}$} & \multirow{2}{*}{ NR } \\
\hline & & & SARME: 4 & $>6$ & $C B C 1$ & 0 & $\begin{array}{c}1 \text { months: } \\
\text { AE: } 2.25 \text { (SD 1.79); } \\
\text { PE: } 0.5 \text { (SD 0.24) }\end{array}$ & $\begin{array}{c}\text { months: } \\
\text { Canine: } \\
5.33 \text { (SD 2.42); } \\
\text { Molar: } \\
10 \text { (SD 1.4) } \\
\end{array}$ & $\begin{array}{c}6 \text { months: } \\
\text { AE: }-0.74 \text { (SD 0.63); } \\
\text { PE: } 0.8 \text { (SD 0.54) }\end{array}$ & \begin{tabular}{|c|}
6 months: \\
Canine: \\
-0.56 (SD 0.38); \\
Molar: -1.86
\end{tabular} & & & \\
\hline \multirow{2}{*}{$\begin{array}{l}\text { Moralis et } \\
\text { al. [26] }\end{array}$} & \multirow{2}{*}{2016} & \multirow{2}{*}{32} & \begin{tabular}{|l|} 
Segmental \\
LFI: 18 \\
\end{tabular} & \multirow{2}{*}{ NR } & \multirow{2}{*}{$\begin{array}{l}\text { Dental } \\
\text { cast }\end{array}$} & 10.6 & & & & & $\begin{array}{l}\text { AE: } 1.4 ; \\
\text { PE: } 2.1\end{array}$ & & \\
\hline & & & \begin{tabular}{|c|} 
SARME: \\
14
\end{tabular} & & & 36.4 & NR & NR & NR & NR & $\begin{array}{l}\text { AE: } 8.4 ; \\
\text { PE: } 5.5\end{array}$ & NR & $\mathrm{NR}$ \\
\hline
\end{tabular}

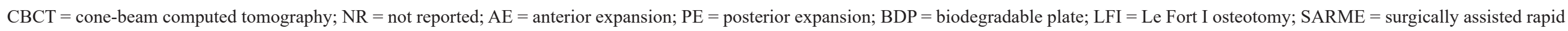
maxillary expansion; $\mathrm{n}=$ number. 
Both treatment modalities significantly increase the transverse dental width of the maxilla, but the overall relapse rate was more pronounced with a tooth-borne SARME. However, the correlation between the transverse dental expansion and relapse with the two treatment modalities was not compared by statistical methods.

CBCT obtained preoperatively and 1 month postoperatively showed that the anterior and posterior dental arch expansion was 1.01 (SD 0.68) $\mathrm{mm}$ and 2.17 (SD 0.90) $\mathrm{mm}$ with a segmental Le Fort I osteotomy, and 5.33 (SD 2.42) $\mathrm{mm}$ and 10 (SD 1.4) $\mathrm{mm}$ with a tooth-borne SARME, respectively [25]. The transverse dental relapse as evaluated by measurements obtained from 1 month postoperatively to 6 months postoperatively showed that the anterior and posterior dentoalveolar relapse was 0.39 (SD $0.24) \mathrm{mm}$ and 0.77 (SD 0.38) $\mathrm{mm}$ with a segmental Le Fort I osteotomy, and 0.56 (SD 0.38 ) $\mathrm{mm}$ and 1.86 (SD 1.75) $\mathrm{mm}$ with tooth-borne SARME, respectively. The change in the dental width expansion and relapse was significantly with a segmental Le Fort I osteotomy, while the dental expansion was significantly increased with SARME. However, the dental relapse was not significantly change compared to the dental expansion achieved with tooth-borne SARME.

\section{Summary}

$\mathrm{CBCT}$ and dental cast measurements revealed that maxillary transverse dental arch expansion and relapse seem to be substantial higher with a toothborne SARME compared to a segmental Le Fort I osteotomy.

\section{Definitive transverse dental arch expansion}

Definitive transverse dental arch expansion has been reported in three studies $[\underline{4}, \underline{24}, \underline{26}]$. Plaster models measurements demonstrated an inter-canine expansion of $1.75 \mathrm{~mm}$ (range 0 to $5 \mathrm{~mm}$ ) and an inter-molar expansion of $3.25 \mathrm{~mm}$ (range -1 to $5 \mathrm{~mm}$ ) with a segmental Le Fort I osteotomy and an inter-canine expansion of $5.25 \mathrm{~mm}$ (range 2.5 to $9 \mathrm{~mm}$ ) and an inter-molar expansion of $5.25 \mathrm{~mm}$ (range 2.5 to 9.5 $\mathrm{mm}$ ) with a tooth-borne SARME after 24 months [4]. The definitive transverse dental arch expansion was significantly increased in both groups, but no statistical comparison between the two treatment modalities was performed. However, no information was provided, whether the final plaster models were manufactured after completion of the orthodontic treatment.
Linear plaster models measurements obtained preoperatively and after expansion showed an anterior width expansion of $1.4 \mathrm{~mm}$ and posterior width expansion of $2.1 \mathrm{~mm}$ with segmental Le Fort I osteotomy after 10.6 months [26]. The anterior and posterior width expansion was $8.4 \mathrm{~mm}$ and 5.5 $\mathrm{mm}$ with tooth-borne SARME after 36.4 months [24]. The after expansion plaster models cast were manufactured after completion of the orthodontic treatment. The definitive transverse dental arch expansion was significantly increased in both groups, but no statistical comparison between the two treatment modalities was performed.

CBCT measurements demonstrated an inter-canine expansion of 2.13 (SD 2.4) $\mathrm{mm}$ and an inter-molar expansion of 4 (SD 3.7) $\mathrm{mm}$ with a segmental Le Fort I osteotomy and an inter-canine expansion of 6.37 (SD 3.92) $\mathrm{mm}$ and an inter-molar expansion of 5.09 (SD 5.38) $\mathrm{mm}$ with a bone-borne SARME after 9 months [24]. No information was provided, whether the final CBCT was obtained after completion of the orthodontic treatment. The total dental expansion was significantly increased in both groups, but no statistical comparison between the two treatment modalities was performed.

\section{Summary}

The definitive transverse dental arch expansion of the maxilla after a segmental Le Fort I osteotomy has been compared to SARME demonstrating a significant increase in the transverse dental arch width with both treatment modalities. However, SARME seems to facilitate a larger definitive transverse dental arch expansion of the maxilla compared to a segmental Le Fort I osteotomy, but a statistical comparison between the two treatment modalities has never been conducted. Moreover, the transverse maxillary deficit was dissimilar among the groups allocated for segmental Le Fort I osteotomy or SARME and no information was provided in relation to the intended transverse expansion of the maxilla with the two treatment modalities.

\section{Frequency of complications}

No intra- or postoperative complications were reported in two studies $[24,25]$.

Summary

The frequency of complications with the two treatment modalities seems to be low and comparable. 


\section{Patient-reported outcome measures}

No study was identified.

\section{Summary}

Patient-reported outcome measures have never been compared within the same study.

\section{Quality assessment}

The quality of the included studies is summarized in Table 3. All the included studies were considered at high risk of bias. Randomization was not performed in any of the studies. In addition, blinding of outcome assessment, clear explanation of withdrawals and drop-outs, were not included.

\section{DISCUSSION}

The current knowledge about transverse skeletal and dental arch expansion and relapse after segmental Le Fort I osteotomy compared to SARME was assessed in the present systematic review. A total of four studies fulfilled the inclusion criteria $[4,24-$ 26]. All the included studies were characterized by high risk of bias and meta-analysis was not possible due to considerable variation among the included studies. Moreover, the magnitude and location of the transverse maxillary deficiency was dissimilar between the groups allocated for segmental Le Fort I osteotomy or SARME [ $\underline{4}, \underline{25}]$, and none of the included studies provided information about the presurgical orthodontic expansion, or the anticipated transverse dental arch expansion of the maxilla with the two treatment modalities. Consequently, the included studies were not matched according to initial maxillary dental arch width, the initial occlusion and no quantification of the required transverse expansion in each region was described. Therefore, several confounding factors influence the outcome measures and the conclusions of the present systematic review should be interpreted with caution.
Further randomized matched studies comparing the two treatment modalities are therefore required to substantiate the preliminary conclusions of the present systematic review.

A variety of aspects including the location and magnitude of the maxillary transverse deficiency, presurgical orthodontic expansion, length of stabilization period and different maxillary osteotomies may influence the long-term stability after transverse expansion of the maxilla with the two treatment modalities. Segmental Le Fort I osteotomy and SARME provides a dissimilar expansion pattern for correction of maxillary transverse deficiency in postadolescent, and direct comparison of the absolute transverse skeletal and dental expansion and relapse between the two treatment modalities is difficult owing to the inherent differences in the indications for selecting one procedure over the other. In the present systematic review, two studies preferred SARME when the maxillary transverse deficiency was more than $6 \mathrm{~mm}$ and segmental Le Fort I osteotomy when it was below $6 \mathrm{~mm}[\underline{4}, 25]$. However, it is not explained how and where the width of the maxillary transverse deficiency is measured. A multi-piece Le Fort I osteotomy creates a more posterior and parallel skeletal transverse expansion of the maxilla, whereas a two-piece Le Fort I osteotomy expands in a hingelike fashion with more transverse expansion in the posterior maxillary region. Conversely, SARME displayed a more V-shaped opening of the midpalatal suture with greatest amount of transverse widening in the anterior maxillary region declining towards the posterior aspect of the palate, as well as more dental expansion compared to skeletal expansion due to tilting of segments during the distraction process. Similar findings have been described in two of the included studies in the present systematic review $[24,25]$. Seeberger et al. [24] described a parallel segment shift without tilting of the segments with a two-piece Le Fort I osteotomy compared to a slight V-shaped opening from anterior to posterior and segment tilting with bone-borne SARME. Yao et al. [25] reported a greater correlation between dental and skeletal changes with segmental Le Fort I osteotomy,

Table 3. Quality assessment of comparative studies

\begin{tabular}{l|c|c|c|c|c|c}
\hline \multicolumn{1}{c|}{ Study } & $\begin{array}{c}\text { Random selection } \\
\text { in the population }\end{array}$ & $\begin{array}{c}\text { Definition of inclusion } \\
\text { and exclusion criteria }\end{array}$ & $\begin{array}{c}\text { Report of losses } \\
\text { to follow-up }\end{array}$ & $\begin{array}{c}\text { Validated } \\
\text { measurements }\end{array}$ & $\begin{array}{c}\text { Statistical } \\
\text { analysis }\end{array}$ & $\begin{array}{c}\text { Risk of } \\
\text { bias }\end{array}$ \\
\hline Marchetti et al. [4] & No & No & - & Yes & Yes & High \\
\hline Seeberger et al. [24] & No & No & - & Yes & Yes & High \\
\hline Yao et al. [25] & No & No & No & Yes & Yes & High \\
\hline Moralis et al. [26] & No & No & - & Yes & Yes & High \\
\hline
\end{tabular}

- = not relevant. 
indicating bodily separation of the segments, whereas tooth-borne SARME showed noteworthy dental and skeletal tipping. However, the type and placement of the distraction devices may influence the magnitude of transverse maxillary widening by SARME and a bone-borne appliances at the first molar will create a more parallel transverse expansion of the maxilla.

The direction and magnitude of segmental tilting associated with SARME may also be influences by the surgical osteotomies $[\underline{20}, 21]$. The pterygomaxillary junction is considered as an area of resistance to maxillary expansion and it is still debatable whether to perform pterygomaxillary disjunction for the correcting of transverse maxillary deficiencies using SARME. Three-dimensional finite element analysis of stress distribution and displacement of the maxilla following SARME demonstrated that a paramedian osteotomy with pterygomaxillary disjunction is an effective procedure for increasing the transverse expansion of the maxilla with less stress around the anchor teeth [27]. Moreover, a positive correlation has been described between pterygomaxillary disjunction and greater posterior alveolar and palatal expansion, whereas greater anterior dental, alveolar, and palatine expansion was correlated to non-pterygomaxillary disjunction SARME [20,29]. Nevertheless, a recent published systematic review concluded that the literature is inconclusive regarding the effect of pterygomaxillary disjunction on the outcome of SARME [30]. In the present systematic review, pterygomaxillary disjunction varied among the included studies. Bone-borne SARME with pterygomaxillary disjunction opened nearly parallel, while tooth-borne SARME without pterygomaxillary disjunction showed noteworthy dental and skeletal tipping [24,25]. Consequently, pterygomaxillary disjunction should be based on individual requirements including a quantification of the required transverse maxillary expansion in each region.

Preoperative orthodontic expansion has been claimed as one of the main sources of transverse postoperative relapse [9]. Therefore, preoperative orthodontic therapy should be segmentalized without any attempt to expand the dental arch perimeter prior to a segmental Le Fort I osteotomy. Moreover, widening of the maxillary dental arch with SARME as a preliminary procedure should be considered in transverse maxillary deficiencies with wide black buccal corridors and dental crowding, to avoid increased risk, inaccuracy, and instability associated with a segmental Le Fort I osteotomy. Therefore, the amount and location of the anticipated dental arch expansion is an important factor in case selection for treatment of maxillary discrepancies in postadolescent patients. Consequently, the treatment planning should include a meticulous clinical and radiographic examination of the maxillary arch form and symmetry, dental crowding, unilateral or bilateral cross-bite, shape of the palatal vault, width of the buccal corridors, occlusion, and predominant mode of breathing or other facial deformities before determining the orthodontic and surgical method and type of distraction device.

The length of the stabilisation period following SARME seems to influence the long-term transverse stability $[9,24]$, and skeletal retention has been recommended for 6 to 12 months [1]. Studies using a six month retention period reported less relapse compared with those that used a three month stabilization period [24]. Various methods have been advocated to reduce the potential for transverse instability after segmental Le Fort I osteotomy $[\underline{5}, \underline{9-}$ 12]. Seeberger et al. [24] used biodegradable plates that were fixed on the nasal floor to stabilize the achieved transverse expansion after segmental Le Fort I osteotomy revealing a stable postoperative results after 9 months. Similar surgical technique has previously been published demonstrating no significant effect on the transverse stability, but a tendency for less relapse in cases with large transverse expansion of the maxilla [9]. Consequently, stabilization of the transverse skeletal expansion with biodegradable plates or autogenous bone block grafts at the palatal osteotomy site may improve the stability after segmental Le Fort I osteotomy, but long-term randomized studies are needed to verify this assumption.

The frequency of intra- and postoperative complications was not reported in all the included studies, but when reported, no surgical or orthodontic complications were described [24,25]. Serious complications after orthognathic surgery involving blindness, death and brain abscess have previously been described in the literature, but the most common complications to segmental Le Fort I osteotomy and SARME comprise pain, infection and bleeding [3134]. Hence, the frequency of intra- and postoperative complications in the included studies seem to low and in accordance with the frequency of reported complications in the literature [34].

Patient-reported outcome measures are essentially subjective reports of patients' perceptions of their oral health status and its impact on their daily life or quality of life. The influence of different oral rehabilitation options on improvement of orofacial aesthetic, chewing function, and oral healthrelated quality of life is an important prerequisite for selection of the best rehabilitation procedure 
for the patient with the highest treatment effect and lowest morbidity. Oral Health Impact Profile questionnaire, Orofacial Esthetic Scale, Diagnostic Criteria for Temporomandibular Disorders (DC/TMD) questionnaire and Chewing Function Questionnaire are commonly used methods for assessment of patient-reported outcome measures. However, none of the included studies assessed patient-reported outcome measures.

The greatest limitation of the present systematic review was that the non-matched study groups as well as the non-uniform study structure, specifically in the selection of surgical procedure, definition of evaluation measurements, outcome measures and variables. There is no standardized measurement for assessment of the skeletal and dental arch expansion and relapse after segmental Le Fort I osteotomy or SARME. Consequently, long-term randomized clinical trials using matched groups and highly accurate three-dimensional measurements to assess the skeletal and dental alterations are needed to increase our knowledge about long-term stability with these two treatment modalities.

\section{CONCLUSIONS}

The hypothesis of no differences in transverse skeletal and dental arch expansion and relapse with segmental Le Fort I osteotomy compared to surgically assisted rapid maxillary expansion could neither be confirmed nor rejected due to insufficient knowledge. Both treatment modalities increase the transverse skeletal and dental arch width of the maxilla. However, the transverse dental arch expansion and relapse seem to be substantial higher with tooth-borne surgically assisted rapid maxillary expansion compared to segmental Le Fort I osteotomy. Considering the methodological limitations of the studies included in the present systematic review, long-term randomized clinical and radiographic studies assessing the transverse skeletal and dental arch expansion and relapse with the two treatment modalities are needed before final conclusions can be provided on this topic. Therefore, further clinical studies involving threedimensional skeletal and dental measurements with more than one year of follow-up after debanding of the orthodontic appliances is recommended

\section{ACKNOWLEDGMENTS AND DISCLOSURE STATEMENTS}

The authors declare that there are no financial or other conflicts of interest related to this publication.

\section{REFERENCES}

1. Betts NJ, Vanarsdall RL, Barber HD, Higgins-Barber K, Fonseca RJ. Diagnosis and treatment of transverse maxillary deficiency. Int J Adult Orthodon Orthognath Surg. 1995;10(2):75-96. [Medline: 9082002]

2. Koudstaal MJ, Poort LJ, van der Wal KG, Wolvius EB, Prahl-Andersen B, Schulten AJ. Surgically assisted rapid maxillary expansion (SARME): a review of the literature. Int J Oral Maxillofac Surg. 2005 Oct;34(7):709-14. [Medline: 15961279] [doi: 10.1016/j.ijom.2005.04.025]

3. Lagravère MO, Major PW, Flores-Mir C. Dental and skeletal changes following surgically assisted rapid maxillary expansion. Int J Oral Maxillofac Surg. 2006 Jun;35(6):481-7. [Medline: 16567079] [doi: 10.1016/j.ijom.2006.01.025]

4. Marchetti C, Pironi M, Bianchi A, Musci A. Surgically assisted rapid palatal expansion vs. segmental Le Fort I osteotomy: transverse stability over a 2-year period. J Craniomaxillofac Surg. 2009 Mar;37(2):74-8. [Medline: 19062299] [doi: 10.1016/j.jcms.2008.08.006]

5. Phillips C, Medland WH, Fields HW Jr, Proffit WR, White RP Jr. Stability of surgical maxillary expansion. Int J Adult Orthodon Orthognath Surg. 1992;7(3):139-46. [Medline: 1291607]

6. Proffit WR, Turvey TA, Phillips C. Orthognathic surgery: a hierarchy of stability. Int J Adult Orthodon Orthognath Surg. 1996;11(3):191-204. [Medline: 9456622]

7. Chamberland S, Proffit WR. Closer look at the stability of surgically assisted rapid palatal expansion. J Oral Maxillofac Surg. 2008 Sep;66(9):1895-900. [Medline: 18718397] [PMC free article: 2556547] [doi: 10.1016/j.joms.2008.04.020]

8. De Backer T, Mommaerts MY, Abeloos JVS, De Clercq CAS, Neyt LF. Long term stability of maxillary expansion by a Le Fort 1 osteotomy with midline split. J Craniomaxillofac Surg. 1996 Aug;24(suppl1):132. [doi: $10.1016 / \mathrm{S} 1010-5182(96) 80608-1]$

9. Kretschmer WB, Baciut G, Baciut M, Zoder W, Wangerin K. Transverse stability of 3-piece Le Fort I osteotomies. J Oral Maxillofac Surg. 2011 Mar;69(3):861-9. [Medline: 21050640] [doi: 10.1016/j.joms.2010.05.024]

10. Matsushita K, Inoue N, Kobori Y, Tei K. New device for palatal expansion in conjunction with the Le Fort I osteotomy. Br J Oral Maxillofac Surg. 2015 Dec;53(10):1038-9. [Medline: 26160161] [doi: 10.1016/j.bjoms.2015.06.016]

11. Reinkingh MR, Rosenberg A. Palatal surgical splint for transverse stability of Le Fort I osteotomies: a technical note. Int J Oral Maxillofac Surg. 1996 Apr;25(2):105-6. [Medline: 8727579] [doi: 10.1016/S0901-5027(96)80051-8] 
12. Charezinski M, Balon-Perin A, Deroux E, De Maertelaer V, Glineur R. Transverse maxillary stability assisted by a transpalatal device: a retrospective pilot study of 9 cases. Int J Oral Maxillofac Surg. 2009 Sep;38(9):937-41. [Medline: 19446437] [doi: 10.1016/j.ijom.2009.04.006]

13. Stokbro K, Aagaard E, Torkov P, Bell RB, Thygesen T. Surgical accuracy of three-dimensional virtual planning: a pilot study of bimaxillary orthognathic procedures including maxillary segmentation. Int J Oral Maxillofac Surg. 2016 Jan;45(1):8-18. [Medline: 26250603] [doi: 10.1016/j.ijom.2015.07.010]

14. Suri L, Taneja P. Surgically assisted rapid palatal expansion: a literature review. Am J Orthod Dentofacial Orthop. 2008 Feb;133(2):290-302. [Medline: 18249297] [doi: 10.1016/j.ajodo.2007.01.021]

15. Verstraaten J, Kuijpers-Jagtman AM, Mommaerts MY, Bergé SJ, Nada RM, Schols JG; Eurocran Distraction Osteogenesis Group. A systematic review of the effects of bone-borne surgical assisted rapid maxillary expansion. J Craniomaxillofac Surg. 2010 Apr;38(3):166-74. [Medline: 19664932] [doi: 10.1016/j.jcms.2009.06.006]

16. Koudstaal MJ, Wolvius EB, Schulten AJ, Hop WC, van der Wal KG. Stability, tipping and relapse of bone-borne versus tooth-borne surgically assisted rapid maxillary expansion; a prospective randomized patient trial. Int J Oral Maxillofac Surg. 2009 Apr;38(4):308-15. [Medline: 19278832] [doi: 10.1016/j.ijom.2009.02.012]

17. Vilani GN, Mattos CT, de Oliveira Ruellas AC, Maia LC. Long-term dental and skeletal changes in patients submitted to surgically assisted rapid maxillary expansion: a meta-analysis. Oral Surg Oral Med Oral Pathol Oral Radiol. 2012 Dec;114(6):689-97. [Medline: 22858019] [doi: 10.1016/j.0000.2012.01.040]

18. Adolphs N, Ernst N, Menneking H, Hoffmeister B. Transpalatal distraction--state of the art for the individual management of transverse maxillary deficiency--a review of 50 consecutive cases. J Craniomaxillofac Surg. 2014 Dec;42(8):1669-74. [Medline: 24962044] [doi: 10.1016/i.jcms.2014.05.011]

19. Landes CA, Laudemann K, Schübel F, Petruchin O, Mack M, Kopp S, Sader RA. Comparison of tooth- and boneborne devices in surgically assisted rapid maxillary expansion by three-dimensional computed tomography monitoring: transverse dental and skeletal maxillary expansion, segmental inclination, dental tipping, and vestibular bone resorption. J Craniofac Surg. 2009 Jul;20(4):1132-41. [Medline: 19634218] [doi: 10.1097/SCS.0b013e3181abb430]

20. Pinto PX, Mommaerts MY, Wreakes G, Jacobs WV. Immediate postexpansion changes following the use of the transpalatal distractor. J Oral Maxillofac Surg. 2001 Sep;59(9):994-1000; discussion 1001. [Medline: 11526562] [doi: $10.1053 /$ joms.2001.25823]

21. Matteini C, Mommaerts MY. Posterior transpalatal distraction with pterygoid disjunction: a short-term model study. Am J Orthod Dentofacial Orthop. 2001 Nov;120(5):498-502. [Medline: 11709668] [doi: 10.1067/mod.2001.118401]

22. Welch V, Petticrew M, Tugwell P, Moher D, O’Neill J, Waters E, White H; PRISMA-Equity Bellagio group. PRISMAEquity 2012 extension: reporting guidelines for systematic reviews with a focus on health equity. PLoS Med. 2012;9(10):e1001333. [Medline: 23222917] [PMC free article: 3484052] [doi: 10.1371/journal.pmed.1001333]

23. Higgins JPT, Altman DG, Sterne JAC. Chapter 8: assessing risk of bias in included studies. In: Higgins JPT, Green S, editors. Cochrane handbook for systematic reviews of interventions version 5.1.0 (updated March 2011). The Cochrane Collaboration. 2011. [URL: http://handbook.cochrane.org/]

24. Seeberger R, Gander E, Hoffmann J, Engel M. Surgical management of cross-bites in orthognathic surgery: Surgically assisted rapid maxillary expansion (SARME) versus two-piece maxilla. J Craniomaxillofac Surg. 2015 Sep;43(7):110912. [Medline: 26109236] [doi: 10.1016/j.jcms.2015.05.012]

25. Yao W, Bekmezian S, Hardy D, Kushner HW, Miller AJ, Huang JC, Lee JS. Cone-beam computed tomographic comparison of surgically assisted rapid palatal expansion and multipiece Le Fort I osteotomy. J Oral Maxillofac Surg. 2015 Mar;73(3):499-508. [Medline: 25488314] [doi: 10.1016/i.joms.2014.08.024]

26. Moralis A, Zitzmann K, Gosau M, Schlegel D. The effects of surgical expansion of the maxillary arch and its consequences for the incisor axis. J Craniomaxillofac Surg. 2016 May;44(5):569-73. [Medline: 26976697] [doi: 10.1016/j.jcms.2016.02.002]

27. Han UA, Kim Y, Park JU. Three-dimensional finite element analysis of stress distribution and displacement of the maxilla following surgically assisted rapid maxillary expansion. J Craniomaxillofac Surg. 2009 Apr;37(3):145-54. [Medline: 19028107] [doi: 10.1016/j.jcms.2008.10.002]

28. Laudemann K, Petruchin O, Mack MG, Kopp S, Sader R, Landes CA. Evaluation of surgically assisted rapid maxillary expansion with or without pterygomaxillary disjunction based upon preoperative and postexpansion 3D computed tomography data. Oral Maxillofac Surg. 2009 Sep;13(3):159-69. [Medline: 19714376] [doi: 10.1007/s10006-009-0167-3]

29. Laudemann K, Santo G, Revilla C, Harth M, Kopp S, Sader RA, Landes CA. Assessment of surgically assisted rapid maxillary expansion regarding pterygomaxillary disjunction using thin volume-rendering technique: in variance analysis and in reliability, accuracy, and validity. J Oral Maxillofac Surg. 2011 Oct;69(10):2631-43. [Medline: 21474227] [doi: 10.1016/i.joms.2010.12.007]

30. Hamedi Sangsari A, Sadr-Eshkevari P, Al-Dam A, Friedrich RE, Freymiller E, Rashad A. Surgically Assisted Rapid Palatomaxillary Expansion With or Without Pterygomaxillary Disjunction: A Systematic Review and Meta-Analysis. J Oral Maxillofac Surg. 2016 Feb;74(2):338-48. [Medline: 26187360] [doi: 10.1016/j.joms.2015.06.161] 
31. Ho MW, Boyle MA, Cooper JC, Dodd MD, Richardson D. Surgical complications of segmental Le Fort I osteotomy. Br J Oral Maxillofac Surg. 2011 Oct;49(7):562-6. [Medline: 20965624] [doi: 10.1016/j.bjoms.2010.09.018]

32. Steel BJ, Cope MR. Unusual and rare complications of orthognathic surgery: a literature review. J Oral Maxillofac Surg. 2012 Jul;70(7):1678-91. [Medline: 21821325] [doi: 10.1016/j.joms.2011.05.010]

33. Lanigan DT, Mintz SM. Complications of surgically assisted rapid palatal expansion: review of the literature and report of a case. J Oral Maxillofac Surg. 2002 Jan;60(1):104-10. [Medline: 11757020] [doi: 10.1053/joms.2002.29087]

34. Jędrzejewski M, Smektała T, Sporniak-Tutak K, Olszewski R. Preoperative, intraoperative, and postoperative complications in orthognathic surgery: a systematic review. Clin Oral Investig. 2015 Jun;19(5):969-77. [Medline: 25804886] [PMC free article: 4434857] [doi: 10.1007/s00784-015-1452-1]

\section{To cite this article:}

Starch-Jensen T, Blæhr TL.

Transverse Expansion and Stability after Segmental Le Fort I Osteotomy versus Surgically Assisted Rapid Maxillary Expansion: a Systematic Review

J Oral Maxillofac Res 2016;7(4):e1

URL: http://www.ejomr.org/JOMR/archives/2016/4/e1/v7n4e1.pdf

doi: $10.5037 /$ jomr.2016.7401

Copyright (C) Starch-Jensen T, Blæhr TL. Published in the JOURNAL OF ORAL \& MAXILLOFACIAL RESEARCH (http://www.ejomr.org), 28 December 2016.

This is an open-access article, first published in the JOURNAL OF ORAL \& MAXILLOFACIAL RESEARCH, distributed under the terms of the Creative Commons Attribution-Noncommercial-No Derivative Works 3.0 Unported License, which permits unrestricted non-commercial use, distribution, and reproduction in any medium, provided the original work and is properly cited. The copyright, license information and link to the original publication on (http://www.ejomr.org) must be included. 